\title{
Análise das limitações, estratégias e perspectivas dos trabalhadores com LER/DORT, participantes do grupo PROFIT-LER: um estudo de caso
}

\author{
Analysis of the limitations, strategies and perspectives \\ of the workers with RSI/WRMD, participants \\ of the PROFIT-LER Group: a case study
}

Juliana da Costa Santos Pessoa ${ }^{1}$

M aria Claudia Gatto Cardia ${ }^{2}$

M aria Luiza da Costa Santos ${ }^{3}$

${ }^{1}$ Coordenação do Curso de

Fisioterapia, Centro

Universitário de oão

Pessoa. Camposdo Unipê, BR 230, Km 22, Água Fria. 58053-000 João Pessoa PB. jullycs.fisio@gmail.com

${ }^{2}$ UniversidadeFederal da

Paraíba.

${ }^{3}$ Instituto Federal de

Educação, Ciênciae

Tecnologia da Paraíba.
Abstract This study had as aim to analyze the limitations, strategies and perspectives of the workers with RSI/WRMD, participants of the PROFIT - LER group, of the U niversidade Federal da Paraíba. So, individual interviews were realized, using a recorder and a form, that involved questions related to the pain, functional limitation, motivational factors, strategies, expectations about the physical therapeutic treatment, life's perspective after the treatment and knowledge level about the pathology. By collecting information through a form and analyzing it based on the literature, it was possible to know that the participants have pain and functional limitations; that the PROFIT-LER program offered more information to the participants about the pathology; that kinesiotherapy was the strategy most practiced. Regarding the perspectives, the participants intended to continue to practice what they learnt in the group, and also look for another treatment options, becausethis treatment allowed socialization between the workers and moreknowledgeabout the pathology. So, thestudy had success as it reached the proposed objective and to make clear that the human is exposed to factors that can change its physical and mental equilibrium, unchaining pathologic process.

Key words Limitations, Perspectives, Strategies
Resumo Este estudo teve como finalidade analisar as limitações, estratégias e perspectivas dos trabalhadores com LER/DORT, participantes do grupo PROFIT-LER, da Universidade Federal da Paraíba. Para tanto, foram realizadas entrevistas individuais, utilizando um gravador e um formulário, que abrangeu questões relacionadas com dor, limitação funcional, fatores motivacionais, estratégias, expectativas em relação ao tratamento fi sioterapêutico, perspectiva devida apóso tratamento e grau de conhecimentos acerca da afecção. M ediante os dados obtidos através do formulário eanalisados à luz da literatura utilizada sel ecionada, foi possível constatar que os pesquisados apresentaram dores elimitações funcionais; que o programa PROFIT -LER ofereceu um maior conhecimento para os partici pantes acerca da patologia; quea estratégia maisutilizada foi a cinesioterapia; eque, quanto às perspectivas, os pesquisados pretendem continuar a praticar o que aprenderam com o grupo, assim como procurar outras formas de tratamento, uma vez que este tratamento permitiu socialização entre os trabalhadores e um maior conhecimento sobrea afecção. Desta forma, o estudo obteve êxito por alcançar o objetivo proposto e por esclarecer que o ser humano está exposto a fatores que podem alterar seu equilíbrio físico e mental, desencadeando processos patológicos.

Palavras-chave Limitações, Perspectivas, Estratégias 
Introdução

Atualmente, os trabal hadores têm que se adaptar às tecnologias e se atualizar perante um mercado competitivo. Diante destas situações, o ser humano está envolvido num processo complexo e dinâmico que abrange as condições somáticas, os processos cognitivos e emocionais, e as questões sociais. O bserva-se, então, que os trabal hadores são atingidos por estas transformações, que ocorrem num ritmo elevado, muitas vezes maior que a própria capacidade humana pode suportar. Dentre os danos causados aos trabaIhadores, destacam-se as lesões por esforços re petitivos (LER)/distúrbios osteomusculares re lacionados ao trabalho (DORT) $)^{1,2}$.

As LER/DORT são caracterizadas pela incapacidade laboral temporária ou permanente, re sultante da combinação de sobrecarga do sistema osteomuscular com a falta de tempo para a recuperação e com a organização do trabalho ${ }^{3}$.

É comum que esta doença resulte em alterações nos vários aspectos da vida do trabalhador. A presença de dores e limitações, decorrentes da patologia, contribui para o surgimento de sintomas depressivos e de ansiedade, acompanhados deangústia e medo em relação a um futuro incerto. A partir destas modificações, o trabalhador perdeum pouco da sua identidadeeganha insegurança no ambiente de trabalho, familiar e social.

0 processo de reintegração e conscientização é difícil de ser executado, pois sofre resistências denatureza individual e organizacional. As resistências individuais estão relacionadas com as barreiras impostas pelo próprio trabalhador, que exige muito de si mesmo e que tem dificuldade em perceber os seus limites, aceitá-los e respeitáIos. Já as resistências organizacionais estão associadas à dificuldade de modificar o posto de trabalho para uma melhor atuação do trabalhador.

Se sob o ponto de vista social, os trabal hadores com LER/DORT sofrem descrédito quanto aos efeitos da doença; sob o ponto de vista da legislação previdenciária, eles encontram obstáculos para o reconhecimento da patologia devido aos trâmites burocráticos e à necessidade de provar a sua existência e sua relação com a atividade laboral.

Assim, este trabal ho busca investigar o efeito da dor no dia a dia dos portadores de LER/DORT, suas limitações e suas perspectivas em relação ao programa PROFIT-LER, da Universidade Federal da Paraíba.

\section{Referencial teórico}

Dor

Para Wood", a dor "é uma combinação de sensações subjetivas que acompanham a ativação de nociceptores". A sensação dolorosa envolve aspectos físico-químicos da nocicepção, como também componentes socioculturais do indivíduo eas particularidades do ambienteonde o evento nociceptivo ocorreu. Estas sensações podem variar desde uma leve irritação até uma dor intensa. Apesar de causar desconforto, a dor é um mecanismo protetor do corpo humano que informa sobre a localização e intensidade dos estímulos dolorosos aos tecidos do organismo 5 .

A dor em pacientes com LER édecorrentedas alterações morfofuncionais adaptativas dos tecidos, quando expostos aos fatores de risco no ambiente laboral. Estas modificações associadas a eventos traumáticos físicos e/ou emocionais podem, além da dor, desencadear incapacidade funcional e sofrimento psicoafetivo ${ }^{5}$.

Como a dor é o principal sintoma da LER, em 1988, Dennet eFry a classificaram em quatro graus, considerando a localização e os fatores agravantes:

-Grau 1: dor localizada, sensação de peso e desconforto no membro afetado; caracterizada como em pontadas, que surgem ocasionalmente durantea jornada de trabalho, mas não interfere na produtividade; melhora com o repouso; éleve; sinais clínicos ausentes;

. Grau 2: dor em vários locais durante a atividade, éintermitenteetolerável; permiteo desempenho da atividade profissional, mas já há uma redução da produtividade nos períodos de exacerbação; pode estar acompanhada de formigamento e calor, além de leves distúrbios de sensibilidade; pode ainda existir uma irradiação;

- Grau 3: podesurgir em repouso ecausar perda de função muscular e parestesia; é persistente, fortee tem irradiação mais definida; o repouso só alivia a dor; há sensível queda da produtividade; sinais clínicos presentes, edema é frequente e recorrente; hipertonia muscular constante; alterações de sensibilidade são mais presentes e acompanhadas de palidez, hiperemia e sudorese nas mãos; 0 retorno à atividade é problemático;

. Grau 4: dor presenteem qual quer movimento da mão; presença de dor após atividade com mínimo de movimento, em repouso e à noite; aumento da sensibilidade; perda da função motora; éintensa, contínua einsuportável; há perda da força muscular e do controle dos movimen- 
tos; edema é persistente; podem surgir deformidades. A capacidade de trabalho é anulada e os atos da vida diária são também prejudicados. N este estágio, são comuns quadros de depressão, ansiedade e angústia.

\section{Incapacidade funcional}

Segundo a American M edical Association, incapacidadeéa perda limitanteou impossibilidadedo indivíduo de atender às demandas pessoais, sociais ou ocupacionais ou às exigências estatutárias ou regulamentares ${ }^{7}$. Já Laurenti ${ }^{8}$, em 1992, definiu incapacidade como qualquer redução ou falta de capacidade para executar a atividade dentro dos limites considerados normais para o ser humano.

A incapacidade funcional correspondeà dificuldade de manter as habilidades físicas e mentais necessárias a uma vida independente. Assim, a manutenção da capacidade funcional do indivíduo acometido por determinada afecção significa a valorização da autonomia e da autodeterminação, como também a preservação da independência física e mental do indivíduo ${ }^{9}$.

Reações comportamentais desencadeadas pela dor e incapacidade

em portadores de LER/DORT

As alterações fisiológicas, psicológicas e psicossociais são evidentes nestes pacientes; entretanto, a percepção dos estímulos dolorosos pode ser modificada pelo estado psíquico do paciente, cabendo ressaltar que a dor crônica pode produzir incapacidade para as atividades profissionais, sociais efamiliares. 0 comportamento do indivíduo com dor crônica é caracterizado por sinais físicos da doença e pela ocorrência de depressão, ansiedade, insegurança, hostilidade, adoção de posturas introvertidas e do período de repouso com consequências financeiras e sociais $5^{5}$.

A limitação física neste paciente gera inape tência e contribui para o agravamento das anormalidades comportamentais psíquicas. A atividade da vida diária, o lazer, o sono e o apetite são também comprometidos. Assim, a dor persistente, a incapacidadefísica, a preocupação com a não cura da doença, a perda da importância no ambiente social, profissional e familiar, as perdas econômicas e a sensação de abandono são fatores que contribuem para o surgimento da depressão, já que para muitos trabalhadores, as suas atividades definem o que eles são, 5,10 .

A hostilidadeédecorrenteda evolução da afecção como também da presença de resultados in- satisfatórios das terapias. Já a incapacidade física e o sofrimento causam redução do rendimento profissional, resultando no afastamento do ambiente laboral, que traz como consequências repercussões econômicas, agravadas pelos custos dos procedimentos terapêuticos. Da mesma maneira, a perda de autoestima, influenciada pelas alterações físicas, modifica a autoimagem do paciente, levando-o a vivenciar um sentimento de culpa, que pode ser direcionado a si próprio ou aos fatores laborativos. Este sofrimento pode ainda alterar o relacionamento familiar, causando depressão, ansiedade e desespero $0^{5,10,11}$.

Conforme Araujo e N unes ${ }^{11}$, a incompreensão, o preconceito e a cobrança das pessoas são reações também sentidas pelos portadores de LER/D ORT, enfatizando o sentimento deculpae mobilizando sentimentos de humilhação e marginalização. Assim, écomum o paciente buscar o isolamento social.

Aspectos psicossociais

da saúde do trabalhador: motivação

Geralmente, a motivação é abordada como um processo de satisfação denecessidades, sabendo-se que o termo necessidade significa estado interno quefaz com que os resultados sejam atraentes. U ma necessidade insatisfeita cria tensão, gerando um comportamento de busca para atingir determinada meta que, se atingida, satisfará a necessidade e resultará na redução da tensão ${ }^{12}$.

A motivação pode ser de origem externa ou interna ${ }^{13}$ :

. M otivação interna: caracterizada por um conjunto de percepções que uma pessoa tem em relação a sua existência, estando relacionada à autoestima e reconhecimento que a pessoa tem em relação a si mesma. É o principal aspecto da motivação, já que é o mecanismo intrínseco que "move" o indivíduo, mantendo-o disposto, permitindo seu desenvolvimento;

- M otivação externa: é um conjunto de valores e visão de certo ambiente que propicia relações interpessoais adequadas, dentro de um clima que favorece a realização plena das pessoas que atuam neste ambiente. Os elementos deste ambiente devem oferecer estímulos para as pessoas, como também serem capazes de gerar relações de causa e efeito nos comportamentos das pessoas e os resultados esperados pela empresa.

Segundo Castro13, a motivação é um processo que promove estímulos e interesses nas pessoas eque estimula comportamentos e ações. Logo, mediante oportunidades e estímulos adequados, 
as pessoas trabalham maismotivadase com maior entusiasmo. Desta forma, ela é um processo interno que sofre influências dos fatores externos, que atuam como fatores desencadeadores ${ }^{12}$.

\section{M etodologia}

0 estudo correspondeu a uma pesquisa descritiva e exploratória que, quanto aos meios de investigação, foi caracterizado como estudo de caso, pois se limitou a um grupo de trabalhadores, portadores de LER/DORT, que participaram do programa PROFIT-LER, desenvolvido no Departamento de Fisioterapia da Universidade Federal da Paraíba. 0 universo da pesquisa foi composto pelos trabalhadores do grupo PROFIT-LER, perfazendo um total de nove trabalhadores.

Os dados foram coletados por meio de um formulário aplicado a cada trabalhador, através da técnica de entrevista. As informações obtidas foram registradas por um gravador e as respostas verbais dos participantes foram transcritas na íntegra para uma planilha. Este formulário, caracterizado por perguntas abertas, conteve informações sobre a dor, vivenciada pelo trabalhador; as estratégias usadas para conviver com a patologia; os fatores motivacionais; as expectativas em relação ao tratamento fisioterapêutico e as perspectivas de vida após o tratamento; e os conhecimentos obtidos durante atividade em grupo.

Os dados também foram coletados durante as reuniões, desenvolvidas com o grupo, nas terças-feiras, às 10 horas, na sala de exercícios terapêuticos. Estes dados estão diretamente relacionados com a programação teórico-prática elaborada.

Os dados obtidos foram tratados de forma qualitativa e quantitativa. A abordagem qualitativa enfatizou os indicadores quanto à dor, limitação funcional, estratégias utilizadas para conviver com a patologia, fatores motivacionais, expectativas em relação ao tratamento fisioterapêutico e perspectivas de vida após o tratamento; já a abordagem quantitativa registrou os indicadores referentes ao grau de conhecimento acerca da patologia, através de medidas estatísticas descritivas.

\section{Resultadosediscussão}

Perfil dos participantes

do grupo PROFIT-LER

0 universo da pesquisa foi composto por nove trabal hadores de diversas áreas, sendo sete do sexo feminino edois do sexo masculino, que participam do grupo PROFIT-LER.

Conforme Couto ${ }^{14}$, Egri ${ }^{15}$ e Frigeri e Vidal ${ }^{16}$, as mulheres são mais acometidas por LER/DORT, já que elas possuem $33 \%$ menos força muscular devido a um menor número de fibras musculares e menor capacidade de armazenar e converter o glicogênio em energia. Além do que, elas realizam uma dupla jornada de trabalho: trabaIho externo e atividades domésticas, tornandoas mais suscetíveis a essa doença.

Carneiro ${ }^{17}$ afirma que os postos de trabalho ocupados por mulheres geralmente são menos qualificados. Além do que, elas têm menos acesso aos programas de treinamento, realizam trabal hos destituídos de conteúdo, fragmentados e executados em tempos impostos.

A faixa etária dos pesquisados delimitou-se a $11,1 \%$ com a idadeentre $20-29$ anos; $22,2 \%$ entre 30-39 anos; $44,5 \%$ entre $40-49$ anos e $22,2 \%$ com a idade entre 50-59 anos, sendo a idade mínima de 28 anos e a idade máxima de 59 anos.

A maior incidência de portadores com LER/ DORT ocorreu na faixa etária de 30-40 anos, acometendo os trabal hadores no auge de sua produtividade e experiência profissional ${ }^{15,18}$.

\section{Avaliação da limitação funcional}

A limitação funcional, considerada como uma das consequências mais marcantes para o paciente, dificulta a realização de suas atividades, sejam domésticas, do trabalho ou até mesmo de lazer. Estes pacientes estão em uma situação de constante sofrimento físico e psíquico ${ }^{19}$.

As justificativas dos entrevistados, para esta questão, estão transcritas abaixo.

Em casa atrapal ha porque eu não consigo arrumar nada, fazer comida pra mim é um sacrifício, pegar aquelestubos de leite pra mim éuma dificuldade, mas eu pego, mas geralmente derrubo, na maioria das vezes deixo cair. Eu tenho meu rapazinho de sete anos, desde que eu comecei a sentir dor, 
tento evitar pegar no colo, pegar peso, primeiro porque eu não consigo fazer. Eu digito muito menos, acho que eu digito nem a metade do que eu digitava, por questão da dor. (paciente M S.S.F.)

Eu tenho dificuldade de lavar qualquer roupa, uma calça jeans, eu não lavo, uma blusinha de malha ainda lavo. Enxáguo toalha, mas não consigo espremer, roupa nenhuma consigo espremer. Faço um arroz, varro uma casa, passo um pano, mas quando termino, tô com o braço que não me aguento, tá quei mando, doendo. $\mathrm{N}$ o trabalho, dificultava a varrer quando eu fazia assim, dobrava o braço, que tinha que puxar a lã embaixo das máquinas. Aí, tinha que ser com as duas mãos. (pacienteM.S.L.)

Quando pega assim a dor, você não pode fazer nada, não podetrabalhar, nem no meu caso queeu não posso nem estudar porque eu faço o curso de música, aí eu não consigo nem terminar as cadeiras que eu tô pagando. Eu não consigo depois de carregar as caixas, relaxar completamente os dedos, vou tocar meio tenso. (pacienteJ.R.)

0 trabalho que eu tinha era muito forte, minhas atividades eram muito mais presentes. M eus pratos, eu não lavo, deixo na pia, tenho horror a deixar coisa suja, masaí eu jogo na cozinha. O utros serviços domésticos eu não faço mais; tomar banho, lavo 0 cabelo no cabeleireiro. (paciente M.R.)

Diante destas respostas, a limitação funcional interferiu tanto na execução da atividade profissional como na relação familiar ena execução das atividades domésticas. $\mathrm{N}$ a verdade, ela contribui para o processo de alteração da autoimagem dos trabalhadores.

Para Araujo e N unes ${ }^{11}$, a modificação da autoimagem do paciente não só ocorre no aspecto da limitação física, que dificulta ou até mesmo impede o exercício da profissão, como também promove a perda do prestígio e do reconhecimento. Além da perda da autoestima, há alteração da identidade que se estende para outros papéis, principal mentepara aqueles desempenhados em família, mexendo com a imagem de "che fe da família". Já as mulheres expressam angústia pela dificuldade de cuidar dos filhos ou para de sempenhar as atividades domésticas. Outro aspecto relevante é o comprometimento nas relações afetivas e no desempenho sexual.

Asalterações, referentes à autoimagem do trabalhador, estão relacionadas com o desequilíbrio entre a dificuldade no diagnóstico e os sintomas apresentados que repercutem em fal tas no trabaIho. Logo, os trabalhadores com LER/D O RT são rotulados de "gazeteiros" e a patologia é denominada como o "mal dos preguiçosos" 20 .

\section{Avaliação da dor}

A dor, nos pacientes com LER/DORT, é um dos fatores limitantes, que comumente está presente, sendo de caráter persistente, mesmo com tratamento.

É uma dor constante, masnão étão insuportável. Todos os dias, todas as horas, eu sinto dor, mesmo tomando medicamento. Ela émoderada, diminuiu assim porque agora eu não me sinto tão estressada. A dor percorre todo o meu corpo e a que mais me incomoda é esta parte aqui [região do abdome] porque está incomodando a minha respiração ultimamente. (paciente C.S.)

Ela é contínua. Passa o dia me incomodando, mas não é uma dor forte, não éinsuportável, ela é bem moderada, geralmente, na sexta-feira, eu sinto mais dor. $\mathrm{Na}$ segunda, geralmente tô mais relaxada, estou melhor, mas sempretem aquela dorzinha que tá semprelá. Diminuiu muito, depois que eu comecei o tratamento aqui. ( paciente M.S.F.)

Essa dor é constante. Começava a inchar, adormecer ea formigar, começava aquela dor nos nervos, subindo pro braços. Devido à dor que eu sinto na coluna e nesse braço, eu durmo pouco, durmo mal. Quando eu tava trabalhando, era constante, era insuportável. Quando eu começo a movimentar, começa a aumentar, como se ela estivesse se renovando, inflamando tudo. Quando eu vou me deitar, ela me machuca, até na cama ela dói. (pacienteM .S.L.)

Antes, ela tinha sido muito forte ao ponto de eu levar a escarcela na cabeça porque os movimentos dos braços quando eu faço esse movimento pra lá pra cá, então esse movimento repetitivo até do caminhar do braço, ela interfere. (paciente M.R.)

Estes relatos confirmam quea dor realmente correspondea um processo limitante para os trabalhadores, interferindo tanto no aspecto profissional quanto no aspecto familiar.

Deve-se ressaltar que a dor pode estar relacionada à ansiedade sobre a perda do emprego, à capacidade de percepção eà sensação de desamparo, que intensifica a dor e dificulta o seu controle ${ }^{10}$. 
Análise dos fatores motivacionais

Deacordo com o item motivação, percebe-se nas justificativas dos trabal hadores uma relação entre os fatores motivacionais e a qualidade de vida no trabalho.

Para Canete ${ }^{21}$, o termo qualidade de vida no trabal ho corresponde a um conjunto de ações de uma organização que envolve diagnóstico e implantação demelhorias gerenciais, tecnológicase estruturais, dentro e fora do ambiente laboral, propiciando condições de desenvolvimento humano para e durante a realização do trabalho.

Eu já estou aposentada, até hoje eu não encontrei nada que eu pudesse assumir, meu corpo não suporta uma carga horária, porque a mínima não é seis horas. A qualidade de vida no trabal ho caiu, eu estou buscando ainda o que eu posso fazer, até agora eu não encontrei, eu gostaria de ter uma ocupação. A qualidade de vida está atrelada com qualidade de vida no trabalho, porque trabalho é vida. Quando eu fui afastada do trabalho, eu lutei muito. M eu chefe quis me tirar, mas eu disse: não. $M$ as eu não sabia o comprometimento que este problema me daria. Se eu soubesse, eu não teria agido desta forma, eu fui irresponsável comigo mesmo. Eu adorava o que fazia. Não quero que todo mundo pense em mim como coitadinha porque tem muita coisa pior. Não mata, mas maltrata! (paciente M .L.)

M elhorou porque eu saí do serviço que eu fa$z i a$, que era muito pesado, cansativo. 0 rendimento diminuiu, faço as coisas mais devagar, com calma. (pacienteS.V.)

A doutora queria meaposentar, mas eu nunca quis, Deus me livre me aposentar. A única coisa quemeincomoda épensar em parar detrabal har e os meus bordados. Da dor pra cá, só mudou porque eu diminuí, mas o resto é muito bom. Posso me considerar privilegiada, porque empresa nenhuma ia me aceitar assim. $\mathrm{Na}$ vida familiar, quando eu tava com a dor no pescoço, eu tava de um mal humor que nem eu mesma me aguentava. $\mathrm{Na}$ minha família, todo mundo me ajuda, todos me incentivam. (paciente M.S.F.)

Eu vivia em Brasília sem ninguém. Não tinha uma pessoa que me desse apoio. Em casa, a qualidade devida deixa muito a desejar. Interferemuito de forma negativa. No trabalho, antes de ser afastada, eu não podia ver um colega, que me irritava muito, quando a gerente pedia uma coisa quatro, cinco vezes eu já ficava irritava, ia chorar no banheiro, ela pegava no meu pé. (paciente M.R.)

Percebe-se que, quando os trabalhadores se referem à qualidade de vida no trabalho, estão enfocando as condições organizacionais e estruturais do trabalho que influenciam nas suas necessidades em crescer profissionalmente na organização. A partir do momento que o trabal hador tem suas necessidades atendidas, o seu rendimento e produtividade no trabalho aumentam, favorecendo a empresa, e suas relações familiares e afetivas também são influenciadas positivamente.

Análise das estratégias

utilizadas para conviver com a afecção

As pessoas reagem de maneiras peculiares à doença, existindo, portanto, várias formas de enfrentamento, que dependem das características individuais e do estágio em que se encontra a patologia.

Eu coloco compressa, às vezes eu dou uma massagenzinha, e fico fazendo o que eu aprendi aqui. me alongo. Me ajudou como me levantar, a me abaixar, a apanhar um peso. (pacienteS.V.)

Até o relaxamento, 0 alongamento, 0 acordar, tô fazendo direitinho do jeito que eles mandam porque aí melhora bastante. Muito compressa de gelo. Faço os alongamentos de manhã quando eu acordo. (paciente M.S.F.)

Quando tenho dor, corro logo pro remédio. Nunca faço [alongamento], só aqui. Já preparei uma vassourinha, porque eu gostei muito daquele do pé. (pacienteS.A)

Eu faço os alongamentos, amanheço o dia, me levanto do jeito que foi ensinado aqui, eu alongo os braços, alongo o pescoço. Tudo que me ensinaram, eu faço em casa. 0 cabo da vassoura esfregando no pé, nas mãos também, alongo os dedos, o punho. Faço o relaxamento, a compressa de gelo também. (pacienteM .S.L.)

Nestes relatos, a estratégia mais utilizada foi a cinesioterapia, praticada tanto durante as sessões como também em casa, após orientações. Também foi possível determinar que, além da fisioterapia, al guns participantes ain da fazem uso demedicamentos.

\section{Avaliação das perspectivas quanto ao PROFIT-LER}

A identidade do indivíduo é compreendida como fenômeno histórico e social, caracterizado pelo fato de queaquilo que o indivíduo reconhece como sendo "ele mesmo" é determinado pelo contexto social ondeeleéinserido epor eleinternalizado. Essa identidade precisa constantemente ser reposta pelo ambiente social. M as, as mo- 
dificações impostas pela patologia fazem com que aquilo que o indivíduo reconhecia como sendo sua identidade não se mantenha mais, por não ser mais reposta pela sociedade ${ }^{22}$.

Assim, qualquer grupo de ajuda tem como objetivo principal possibilitar que os trabalhadores com LER/DORT recuperem a sua identidade ese reconheça.

Foi coisa melhor de ter acontecido. É maraviIhoso, todo o tratamento que eu encontrei, todas as clínicas que eu encontrei aqui em João Pessoa, ne nhum foi igual ao que eu encontrei no projeto. Aqui, o tratamento é muito bom, especialmente a pessoa que cuidou de mim. Tem sido $100 \%$, me ajudou $100 \%$, agora é mais importante ou tão importantequanto tá sendo pra mim. É muito bom eu ter encontrado o caminho para viver melhor. (paciente M.L.)

Esse tratamento foi excelente para mim, me ajudou bastante. Eu aprendi uma coisa que eu não sabia, que era os meus direitos. E hoje, eu tenho um pouquinho deforça para correr atrás dele, para ver até onde é o meu limite, para mim seria até melhor seeu continuassenessetratamento por mais tempo. M elhoraria a questão da dor. Para mim isso já é como se fosse um trabalho. É uma coisa quemefaz sentir um pouquinho mais viva porque quando eu parei, fiquei sem trabalhar, senti muita falta. (pacienteC.S.)

Eu gosto, eu acho que a cada dia vai melhorando porqueeu aprendi, primeiro a dormir. Muita coisa mudou com isso, aprendi a conviver com a doença que não aceitava, hoje já aceito. Se eu tô fazendo alguma coisa e chega no meu limite, eu paro. (pacienteS.A)

A partir das primeiras aulas, eu comecei a dormi com uma postura correta, e eu passei a mepoliciar mais. Em relação ao grupo, eu considero que aqui tem bons profissionais, e eu tive orientações, que eu não tive em canto nenhum, nem no Sarah, não tive esse tipo de orientação, de como viver meIhor ede tudo o que esse problema podia acarretar. Foi muito bem elaborado o curso e teve um leque muito grande deassuntos pra gente poder ficar bem informada. Quando a gente capta essas informações, a gente vai policiar melhor a nossa vida. Eu consegui viver melhor, meajudou. (pacienteM .R.)

Pode-se perceber queo tratamento em grupo oferece uma ação-reflexão-aprendizagem, estimulando o exercício afetivo-cognitivo destes trabalhadores, através de palestras, exercícios de relaxamento, dealongamento, derespiração ede correções posturais.

As atividades em grupo permitem a socialização da vivência do adoeci mento e da incapaci- dadefísica, a (re)aprender a buscar recursos para construir estratégias de saúde como também a discutir sobre os medos eas dúvidas dos pacientes em relação ao adoecimento e às dificuldades encontradas no diagnóstico, tratamento e reabilitação. Além do que, as situações de conflito e medo são enfrentadas coletivamente, e as questões referentes à atividade do cotidiano são discutidas para que os trabalhadores possam novamente se apropriar de suas capacidades e buscar novamente o significado do "fazer", considerando as mudanças decorrentes da patologia $a^{23,24}$.

A partir destas atividades, os mecanismos de saúde são construídos com um novo conhecimento decorrente das experiências dos integrantes do grupo ao pensarem, sentirem, agirem, tanto no aspecto individual como no aspecto coletivo. Esse processo de aprendizagem permite 0 desenvolvimento de mudanças na realidade eno próprio indivíduo 24 .

Avaliação das perspectivas de vida após tratamento fisioterapêutico

Não existe 0 após o tratamento fisioterapêutico, até hoje ele faz parte da minha rotina de vida, eu não me vejo sem a fisioterapia, eu não me vejo sem condição deviver sem o tratamento. (paciente M.L.)

Continuar a fazer o quea genteaprendeu aqui. Eu gostaria muito de continuar meu tratamento, e fazer algo assim em relação ao trabalho, que tirasse assim um pouquinho sensação de vazio, a sensação de que eu não vou mais puder trabalhar. (pacienteC.S.)

Você tem uma perspectiva de vida, mas você não pode chegar nela, aí você fica naquele jogo: meu Deus, será que eu tô sendo vagabundo, será queeu tô recusando a trabalhar. Não pretendo procurar outro tratamento de fisioterapia, já fiz acupuntura, meu quadro está bem resumido. Dependendo da minha situação, eu vou tá sempre aqui. (pacienteS.N.)

Quando terminar aqui, eu pretendo continuar meus al ongamentos, meu relaxamento. E no escritório, só falta mudar o suporte do mouse. Não pretendo procurar outro tratamento, tenho muita vontade de fazer o curso de postura. Eu só penso assim: acabou o curso, como será que eu vou ficar? Se eu sentir dor de novo e se voltar tudo de novo? (pacienteM.S.F.)

Percebe-se que a maioria pretende continuar a praticar o que aprendeu com o grupo e a procurar outras formas de tratamento. Constatouse ainda sentimento de culpa em um dos partici- 
pantes, quenão tem perspectiva defuturo. É pre ciso destacar que a descrença, o preconceito e a cobrança das pessoas são reações que reforçam o sentimento de culpa e proporcionam nestes trabalhadores sentimentos de marginalização, humilhação e de dúvida de si mesmos ${ }^{11}$. Essas atitudes decorrem da falta de consenso sobre a LER/D ORT eda visão distorcida do meio social, quea caracteriza como preguiça efingimento dos trabalhadores.

As perspectivas de vida do paciente após tratamento estão relacionadas a sua capacidade em superar as dificuldades decorrentes da patologia, dando lugar à autoconfiança, à medida que o medo e o sentimento de impotência são abordados em grupo. $M$ as, apesar de ainda existirem dificuldades, o indivíduo é capaz de encontrar alternativas, que promovam um bem-estar físico e psicossocial ${ }^{11}$.

Segundo Araujo e N unes ${ }^{11}$, há alternativas individuais e coletivas. As estratégias individuais estão relacionadas à busca de novas atividades profissionais/ocupacionais para melhorar o estado emocional eo respeito a si mesmo; eterapias convencionais e alternativas. Já as estratégias coletivas são participar de sindicatos e associações, atuar em outrasinstituições, divulgar informações.

\section{Outros fatores determinados na entrevista}

Além dos itens propostos no questionário, outros itens relevantes foram apontados pelos participantes durante a entrevista, conforme apontado a seguir:

Fatores organizacionais

0 meu ambientedetrabalho émuito bom, porque eu trabalho com a minha irmã. No trabalho, com essa dor, o rendimento diminuiu, eu digitava, tinha tempo queeu ficava das 8 da manhã até8:30 - 9:00 da noite digitando direto, um intervalo a cada cinquenta minutos, eu já faço menos de cinquenta, antigamente, era direto, não parava nem pra almoçar. (paciente M.S.F.)

0 turno era de oito horas corridas, com meia hora pra almoçar, só tinha pausa pra ir ao banheiro. 0 médico meafastou do trabalho, pra eles[ empregadores] me colocarem em outra função. Daí por diante, eu não tive mais sossego, fiquei visada na empresa. Era na minha cola, se eu fosse pro banheiro, ele ficava atrás. (paciente S.A.)

A doença diminuiu o rendimento no trabalho. Dentro do trabalho, eu me irritava facilmente. A chefia também deixa muito a desejar porque, na proporção que você vai limitando a sua capacida- de no trabalho, você vai sendo mais cobrada pelos profissionais. (paciente M.R.)

A produção diminuiu, e eu estava sempre sendo chamada a atenção. (paciente C.S.)

Constata-sequea jornada detrabal ho, a pressão da chefia, a redução da produção, a presença de riscos ergonômicos influenciavam no desencadeamento da patologia e até no afastamento do trabalho.

Muitosfuncionários recebem pressão dachefia para retomar a produção e ao ritmo anterior ao adoecimento, e as empresas impõem dificuldades para modificar o posto de trabalho ${ }^{2}$. Neste aspecto, o trabal hador sofre discriminação dos colegas e da chefia, sendo alvo de descrédito em relação à limitação eà dor. M oura ${ }^{2}$ ressalta que 0 afastamento do trabalho pode gerar conflitos, insegurança e tensão no trabalhador, além de dúvidas sobre sua melhora ecapacidade de manter-se ou até mesmo retornar ao trabalho.

\section{Ausência de conscientização}

Se eu soubesse que isso poderia acontecer, élógico que eu não teria feito. (paciente M S.F.)

u não sabia, não conhecia a doença, quando 0 médico diagnosticou que era. (paciente S.A)

A partir dessas respostas, verificou-se que a desinformação e a alienação do trabalhador pelo próprio processo de trabalho foram um dos fatores que dificultaram uma maior participação destes trabalhadores, contribuindo para o surgimento da LER/DORT e para o seu agravamento ${ }^{11}$.

Isolamento social

Fiquei em casa, me isolei totalmente, não que ria ir pra lugar nenhum, porque nesse período eu fui muito humilhada. (paciente S.A)

0 isolamento social éuma alternativa de não ter que dar explicação sobre a doença e não sofrer preconceito e a incompreensão das pessoas, seja do ambiente laboral ou até mesmo do ambientefamiliar ${ }^{11}$.

Relação familiar e com colegas

Ela interfere direto e indireto na sua vida familiar, direto, com o pessoal dentro da sua casa, e indiretamente com as pessoas que nos envolvem, que essas pessoas chegam até a interrogar, elas não permitem quea gente tenha um tipo de doença que não aparentemente se externava em mim. Junto com os colegas, a gentenão se sente muito bem com aquele quadro doloroso. (paciente M.R.)

Em casa, fiquei mais grossa, por tudo grita, por tudo reclama, agradeço a Deus por ter um marido muito paciente. $M$ as, a filha não entendia, peguei 
na fase da adolescência, a gente se batia muito. H oje, não, é só bênção. (paciente S.A)

Deve-se ressaltar que o trabalhador, quando afastado do ambiente laboral, perde os contatos sociais na empresa, tornando-se despersonalizado e desumanizado. Logo, o trabalhador encontra-se mais vulnerável para a perda da autoestima e para o sentimento de culpa ${ }^{10}$.

Análise do grau de conhecimentos dos pacientes após PROFIT-LER

Este item determinou o grau de conhecimento dos participantes do grupo sobre as aulas te óricas oferecidas, que abordaram assuntos relacionados à patologia e à situação dos trabal hadores acometidos. Então, foi possível verificar, em relação ao assunto:

- Aspectos da patologia: $55,6 \%$ dos participantes têm conhecimento parcial; $33,3 \%$ conhecimento total e $11,1 \%$ desconheciam o assunto;

. Processo da doença: 55,6\% têm conhecimento parcial; $33,3 \%$ conhecimento total e $11,1 \%$ desconheciam o assunto;

. Orientações posturais: $55,6 \%$ têm conhecimento total e $44,4 \%$, conhecimento parcial;

- Respiração: $66,7 \%$ têm conhecimento total e 33,3\%, conhecimento parcial;

. Sistemas locomotor e nervoso: $66,7 \%$ têm conhecimento parcial; $22,2 \%$, conhecimento total e $11,1 \%$ desconheciam 0 assunto;

. Estresse e ciclo da dor: 55,6\% têm conhecimento parcial, $33,3 \%$, conhecimento total e $11,1 \%$ desconheciam o assunto;

. Aspectos legais: 55,6\% têm conhecimento parcial; $11,1 \%$, conhecimento total e $33,3 \%$ desconheciam 0 assunto.

Conclui-se que o programa PROFIT-LER obteve repercussões positivas nos trabalhadores, já que permitiu um maior conhecimento acerca da afecção. Também foi possível constatar que o programa deve melhorar no que se refere aos aspectos legais, ao estresse e ciclo da dor, e sistema locomotor e sistema nervoso.

\section{Conclusão}

A LER/DORT é considerada como a segunda patologia do trabalho com maior incidência no Brasil e tem como consequência mais frequente a incapacidade laboral. Em relação aos seus sintomas, verificou-se que seus efeitos atingem 0 ser humano como um todo, pois o sofrimento, decorrente da dor e das limitações funcionais, além deo afetar fisicamente, éagravado pela pressão psicoemocional, que abala a identidade do trabalhador pelo fato desta patologia não ser facilmente diagnosticada.

Esta pesquisa buscou analisar algumas características referentes à dor eàs dificuldades enfrentadas pelos portadores na vida diária e no trabalho. Quanto à dor, este sintoma está presente de forma contínua e intensa. Quanto aos fatores psicoafetivos, foram constatados, em alguns participantes, sinais de comprometimento na relação familiar e com amigos, perda da autoestima e da própria identidade, além da questão do isolamento social, comprometendo assim a sua reintegração social, e sua perspectiva de vida pessoal e no trabalho.

Deve-se ressaltar que o grau de informação sobre a patologia por parte dos trabalhadores é um fator decisivo para recuperação e administração da doença no ambiente laboral. Assim, a obtenção de novos conhecimentos sobre a patologia melhorou a autoestima e a perspectiva de vida, como também minimizou a culpa individual. Além do que, o trabalho em grupo permitiu que os portadores de LER/D ORT compartiIhassem sentimentos e vivências com relação à doença e criassem novas estratégias de saúde.

\section{Colaboradores}

JCS Pessoa trabalhou na elaboração do artigo, coleta e análise dos dados; M CG Cardia e M LC Santos orientaram a elaboração da pesquisa. 
1. Fernandes PV. Distúrbios Osteomusculares Relacionados ao Trabalho. [site da Internet] [acessado 2003 abr 23]. Disponível em: http://www.interfisio. com.br/?artigo\&ID =75

2. Moura RJ. Fatores Psicossociais relacionados aos DORTs (Distúrbios Osteomusculares relacionado ao trabalho). [site da Internet] [acessado $2003 \mathrm{Abr}$ 17]. Disponível em: http://www.uol.com.br/prevler/ artigos/fatores_psicossociais_relacionad.httm

3. O’N eill MJS, M orás MC. A Invisibilidade das LER/ DORT. Folha de São Paulo 2001; 28 fev.

4. Wood L. Fisiologia da dor. In: Kitchen S, Bazin S, organizadores. Eletroterapia de Clayton. $10^{\underline{a}}$ ed. São Paulo: Manole; 1996. p. 80-86.

5. Lin TY, Teixeira MJ, Barbosa HF. Fisiopatologia da dor nos doentes com LER. In: Oliveira CR, organizador. Manual Prático de LER - lesões por esforços repetitivos. $2^{a}$ ed. Belo Horizonte: H ealth; 1998. p.191204.

6. Fonseca AG. Lesões por Esforços Repetitivos. Revista Brasileira de M edicina 1998; 55(6):373-376.

7. Caillet R. Compensação do trabalhador. In: Caillet $R$, organizador. Doenças dos tecidos moles. 3a ed. Porto Alegre: Artes Médicas; 1998, p. 467-475.

8. M endes R. Aspectos conceituais da patologia do trabalho. In: Mendes R, organizador. Patologia do trabalho. 4a reimpressão. Rio de Janeiro: Atheneu; 1995. p. 33- 47.

9. M anutenção da capacidade funcional. [site da Internet] [acessado 2004 abr 16]. Disponível em: http:/ /www.saude.pr.gov.br/Projetos_estrategicos/ saude_idoso/capacidade_funcional.htm

10. Ranney D. Mente, corpo, sociedade e ambiente de trabalho. In: Ranney D, organizador. Distúrbios $0 \mathrm{~s}-$ teomusculares relacionados ao trabalho. São Paulo: Roca; 2000. p. 274-302.

11. Araújo AV, Nunes RB. Contribuição da Psicologia - relato de uma experiência com grupos de portadores de LER. In: Oliveira CR, organizador. Manual prático de LER - lesões por esforços repetitivos. 2a ed. Belo Horizonte: Health; 1998, p.319-339.

12. Robbins SP. Motivação no trabalho e recompensas. In: Robbins SP, organizador. Administração: mudanças e perspectivas. São Paulo: Saraiva; 2000. p. $340-368$.

13. Castro AP. Motivação. In: Boog G, Boog M, organizadores. $M$ anual de gestão de pessoas e equipes: estratégias e tendências. V. 1. São Paulo: Gente; 2002. p. 85-107.

14. Couto HA. Novas perspectivas na abordagem preventiva das LER/D ORT - Fenômeno LER/DORT no Brasil. Belo Horizonte: UFM G/FACE; 2000.
15. Egri D. Lesões por Esforço Repetitivo (Distúrbios O steomusculares Relacionado ao Trabalho). In: Yoshinari NH, Bonfá ESDO, organizadores. Reumatologia para o clínico. São Paulo: Roca; 2000. p. 213-222.

16. Frigeri $F$, Vidal MC. Lesões por esforços repetitivos ou distúrbios músculo-esqueléticos relacionados ao trabalho no setor de teleatendimento. In: Anais do IX Congresso Brasileiro de Ergonomia; 1999; Salvador.

17. Carneiro CM. Perfil social da LER. In: OLIVEIRA $C R$, organizador. M anual Prático de LER-lesões por esforços repetitivos. $2^{a}$ ed. Belo Horizonte: Health; 1998, p.63-96.

18. Oliveira CR. Lesão por esforços repetitivos (LER). Rev. Bras. de Saúde Ocupacional 1991; 73(19):59-85.

19. Merlo ARC, Elbern JLG, Merlo ARC, Vaz MA, Vieira PRB, Spode CB. $O$ trabalho entre prazer, sofrimento e adoecimento: a realidade dos portadores de lesões por esforços repetitivos. Psicologia e Sociedade 2003; 15(1):117-136.

20. Orso PJ, Murofuse NT, Matias LV, Marziale MHP. Reflexões acerca das lesões por esforços repetitivos e a organização do trabalho. Rev Online Bibl Prof Joel Martins 2001; 2(2):47-58.

21. Canete I. Qualidade de vida no trabalho: muitas definições e inúmeros significados. In: Bitencourt C, organizador. Gestão contemporânea de pessoas novas práticas, conceitos tradicionais. Porto Alegre: Bookman; 2004. p. 386-406.

22. Lima $A B$, Oliveira F. Abordagem psicossocial da LER: ideologia da culpabilização e grupos de qualidade de vida. In: Codo W, Almeida M CCE, organizadores. Diagnóstico, tratamento e prevenção: uma abordagem interdisciplinar. 4aㅡ ed. Rio de Janeiro: Vozes; 1995. p. 136- 157.

23. Diário Oficial. Revista CIPA 2004; 290:80-86.

24. Heloani JR, Capitão CG. Saúde mental e psicologia do trabalho. São Paulo Perspec 2003; 17(2):102-108.

Artigo apresentado em 03/07/2006

Aprovado em 25/06/2007

Versão final apresentada em 06/08/2008 